\title{
Process Level Social Media Business Value Configuration of SMEs in Saudi Arabia
}

\author{
Anwar Shams Eldin ${ }^{1}$, Awadia Elnour ${ }^{2}$ \\ Department of Business Administration \\ University of Bisha, Bisha, KSA
}

\author{
Rugaia $\operatorname{Hassan}^{3}$ \\ Department of Information Systems \\ University of Bisha, Bisha, KSA
}

\begin{abstract}
The key enabler of strategic design based on IT is process level value; however, few researchers have tackled the mechanisms through which small and medium-sized enterprises (SMEs) can create value at the process level. This study sheds light on the mechanism of creating social media business value at the process level by identifying the interaction effects of social media and IT resources and the mediating role of management's commitment to innovation as an organizational factor. The research model is based on the IT business value approach, quantitative and descriptive methodology is adopted, and the data are analyzed using structural equation modeling. Among the findings based on 301 SMEs in the Kingdom of Saudi Arabia, that management's commitment to innovation is a necessary condition for social media resources to create dynamic capabilities, and the interaction effects between social media resources and IT resources on social media capability have no impact on the value-generation process at the process level. The result improves the understanding of the theoretical implications of social media business value at the process level, which can be used to guide theorizing about IT business value. SME managers, IT designers, and national decision-makers can use the findings to gain strategic advantage through social media platforms.
\end{abstract}

Keywords-Interaction effects of social media and IT resources; process level; SMEs; social media business value; social media capabilities; management's commitment to innovation

\section{INTRODUCTION}

Small and medium-sized enterprises (SMEs) contribute to a country's economic growth despite limited financial resources. In the Kingdom of Saudi Arabia (KSA), SMEs contribute about 33\% of the GDP, often using information technology to challenge competitors in various sectors. The use of social media among business and society is increasing, creating strategic advantage [1]. Only a few studies have investigated how SMEs integrate social media technology into their operations and strategies [2]. However, many studies in the Saudi context have sought to investigate how SMEs can create value from social media [1]. Most previous studies in this field draw on the information technology (IT) business value literature [3], exploring the impacts of IT investment at the business and process levels [4]. Recently, scholars have explored the impact at the country (or macro) level [5].

At the process level, the business value is the impact of IT resources on performance at this level, which can be generated from inter-firm diversity, or complementary resources and capabilities [6], [7] creating unique resources that cannot be easily replicated [7] termed as capability, which can be related to two functions - facilitating the functional activities of an organization, which is functional capability (operational capabilities), or facilitating a transformation of the way an organization conducts its functional processes, which is dynamic capability.

However, the relationship between social media operational and dynamic capability in SMEs has rarely been investigated although work such as this can shed light on the mechanisms that build capabilities.

Complementary resources are those that interact to generate capabilities [8]. Although some scholars have explored how IT resources interact with other organizational resources, only a few studies have investigated how IT resources interact with one another [9]: for instance, the interaction between social media resources and other IT resources has, so far, been neglected [10]. This knowledge gap can be filled by formulating a comprehensive model that demonstrates how IT resources interact to generate value.

Many factors purportedly explain the conditions under which business value is created, namely organizational, industrial and macroeconomic factors [7], [9]. Prior studies have failed to conceptualize in a clear way how these factors influence value generation at different organizational levels, and their results have been inconsistent [9]. Thus, the valuegeneration mechanism at the process level constitutes a gap in the research. In SMEs, managers' strategic decisions are usually influenced by their individual perceptions and characteristics [11]. Thus, management's commitment to using a particular technology or innovation as an organizational factor influences how an organization benefits from using social media. Unfortunately, most previous research has neglected the mechanisms through which this factor affects value generated at the process level.

To exploit the potential of social media to create value in SMEs at the process level, this study explores the mechanism of social media business value creation at the process level, aiming to identify conditions under which social media resources can contribute to creating value at the process level, by investigating the effects of the interaction between social media resources and other IT resources on social media capabilities (operational and dynamic). Moreover, it highlights the linkage between social media capabilities at the process level, and how management's commitment to innovation affects the relation between social media resources and capabilities.

This work is funded by university of Bisha 
This can enable IT managers to improve the techniques they use to manage and implement IT and social media through a better understanding of the ways IT and social media generate value at the process level. In turn, this can enable SMEs in KSA to gain value by extending the marketing of their products and services locally and globally. This is a potential source of competitive advantage [8],[12] and is the key enabler of strategic design based on IT at the process level. Moreover, the first-order impacts of IT at the process level can further contribute to impacts on firm-level performance.

The remainder of this paper is organized as follows: Section II provides an overview literature review, besides hypotheses development. Section III describes the research model. Section IV presents the methodology used to conduct the research. Section V provides discussions of the results and conclusions. Section VI proposes future studies.

\section{LITERATURE REVIEW AND HYPOTHESES}

\section{A. IT Resources and Social Media Resources and Social Media Capbilities Process Level Business Value}

IT resources comprise both tangible and intangible components [13] that reflect how the organization uses these resources to generate value [9].

Social media is an IT resource based on Web 2.0 [14], comprising a wide variety of tools and platforms categorized into types according to their potential [15] that allow organizations to interact and exchange information with their customers efficiently and cheaply [14]. From the resourcebased view (RBV) perspective, social media can be classified into tangible and intangible assets. The former is the infrastructure of the platform [16] while the latter includes information produced through the use of social media by customers and the firm to generate value at the process level [17].

Prior studies have focused on the impact of social media on business value, describing various forms of value that can be generated using social media at the process level in terms of internal value [15], [18]. The outcome of value generation at this level is capabilities [13], [9].

Based on the dynamic capability approach, capabilities are traditionally described hierarchically as existing at various organizational levels [19], [8] or as multi-dimensional constructs generated by a firm's ability to combine, assemble and integrate resources to create strategic advantage [20] Numerous studies have distinguished dynamic capabilities from other capabilities [21], namely operational capability [19]. This classification can provide a comprehensive view of how an organization can perform the various activities that can give insight into IT business value at the process level.

Social media capabilities refer to how a firm uses social media platforms (resources) to generate business value from its activities [4]. Of the few scholars that have conceptualized social media capabilities, the majority have identified social media in terms of functionality (technological features) [22], [15], marketing [23], or strategic functionality [24] or have concentrated on a single organizational level [16]. Thus, prior studies have not provided comprehensive insights into social media operational capabilities concerning their role in business value creation via functionality. Gaining such insights can help to create a roadmap for capability-building mechanisms, which is necessary for designing effective strategies to achieve superior performance compared with competitors.

Previous studies on IT business value indicate that IT resources positively influence capabilities [9]. In a study on the Sudanese banking industry, Shams Eldin [25] found direct impact between IT resources and dynamic capabilities. In the same context Shams Eldin et al [26] found direct relationship between IT resources and IT functional capabilities. Many scholars have built theoretical models to conceptualize how social media resources configure value at process level. Wittkuhn et al. [16], based on RBV and dynamic capability approach, built a conceptual model to investigate how social customer relation management resource impacts social media customer management capabilities and how both can impact social media customer management performance. An empirical study conducted by Trainor et al. [10] found that social media platform usage positively influences social media capabilities. In SMEs in India, Chatterjee and. Kumar Kar [27] found that social media usage facilitates the use of social media marketing, which brings business benefits to the organization. Moreover, the cost has significant impact in adoption of social media market; this may be due to small budget of SMEs. Therefore, we hypothesize the following:

H1. IT resources have a positive impact on social media capabilities.

H1a. IT resources have a positive impact on social media operational capabilities.

H1b. IT resources have a positive impact on social media dynamic capabilities.

H2. Social media resources have a positive impact on social medial capabilities.

H2a. Social media resources have a positive impact on social media operational capabilities.

H2b. Social media resources have a positive impact on social media dynamic capabilities.

\section{B. Social Media Dynamic Capabilities and Operational Capabilities}

Dynamic capabilities result from the transformation of the lower-level capability to confront change in a business environment [21], such as operational capabilities [19], [9]. A few empirical studies have investigated how this is achieved [21]. Pour et al. [28] aimed to investigate the impact of customer relation capabilities on innovation capabilities as dynamic capabilities, the findings of their study indicated to the direct impact of customer relation capabilities on innovations capabilities. In Brazil, Toriani and Angeloni [29] found that use of IT customer relationships management capabilities can support knowledge capabilities as dynamic capabilities. In SMEs based on knowledge management approaches, Cheng and Shiu [30] found a direct relationship between customer involvement and innovation. This is because the strong customer information processing capability enables SMEs to analyze complex information and give new insights from 
customer involvement, thereby creating knowledge benefits that help in innovations in their new product/service. We thus hypothesize the following:

H3. Social media operational capabilities have a positive impact on social media dynamic capabilities.

\section{The Mediating Role of Management Commitment}

Previous literature describes the direct models of IT business value generating. By contrast, the indirect model suggests that the impact of social media resources at the process level is mediated or moderated by organizational factors [31] and that social media resources interact with other organizational resources to generate value at the process level, Trainor et al. [10].

Collectively, these models describe the idea of complementary resources [12], as discussed in prior work [9]. Complementary resources can create unique value to the organization, differentiating it from its competitors.

An example of the factors that can influence the ability of resources to create value and, thus, describe the conditions under which a certain value is created, is organizational factors, which have the potential to influence the relationship between resources and firm performance. Examples include top management's commitment, organizational structure, firm size, location and industry [32].

Management's commitment reflects how managers' individual characteristics influence the way they make decisions [11]. Management's commitment can be categorized by its various forms, such as strategic decision-making, development, digital platform usage, working smarter using available information, conducting action-oriented assessments [33], and commitment to innovation [34]. The present study focuses on how management's commitment to innovation can influence the generation of business value at the process level, which reflects how managers deal with new inventions and technology, such as social media. This also sheds light on management's ability to deal with the impacts of social media on value generation at the process level and provides insights into the role of managers in creating business value [33], in SMEs where the manager plays a central role in the organization.

According to relationship marketing theory, social media usage can be considered an investment relationship between consumers and marketers that influences business value through the meditation of consumer commitment [35]. Thus, in any social network, commitment to the relationship can be considered a mediator between the two parties of a relationship [36]. Following this line of logic, if managers do not commit to developing a relationship between resource usage and capabilities, such a relationship cannot occur. Thus, management's commitment can be considered a mediating factor [37].

Another perspective on how management's commitment influences the relationships between social media usage and performance is based on the innovation system approach and network theory. Nybakk et al. [34] considered innovative commitment a mediator between social networking and economic performance. In the context of SMEs, Cheng and Shiu [30] suggest that the transformation of resources into capabilities requires the commitment of SME managers in developing new capabilities when facing a new market situation, such as the social media environment. This is rarely investigated in SMEs compared with larger firms. To the researchers' knowledge, management's commitment to innovation in SMEs has not received sufficient attention from social media scholars, although managers' decision plays a central role in adopting IT solutions. Accordingly, we hypothesize the following:

H4. Social media usage has a direct impact on management's commitment to innovation.

H5. Management's commitment to innovation has a direct impact on social media capabilities.

H5a. Management's commitment to innovation has a direct impact on social media dynamic capabilities.

H5b. Management's commitment to innovation has a direct impact on social media operational capabilities.

H6. Management's commitment to innovation mediates the relationships between social media usage and social media capabilities.

H6a. Management's commitment to innovation mediates the relationship between social media usage and social media dynamic capabilities.

H6b. Management's commitment to innovation mediates the relationship between social media usage and social media operational capabilities.

\section{Interaction Effect of Social Media and IT Resources}

Previous studies on IT business value emphasize the role of interaction between resources to create new unique resources that can generate superior value at the process level [9], [12]. In the context of social media, Trainor et al. [10] found a positive relationship between the interaction of customer management systems (as an IT resource) and social media resources and a firm's social media customer relationship capabilities. We thus hypothesize the following:

H7. The interaction of social media resources and IT resources has a positive impact on social media capabilities.

H7a. The interaction of social media resources and IT resources has a positive impact on social media dynamic capabilities.

H7b. The interaction of social media resources and IT resources has a positive impact on social media operational capabilities.

\section{RESEARCH MODEL}

Fig. 1 illustrate the relationship between the variables in the study, through a two-level model that was designed to explain how social media resources create value. The model comprises the resource level and the capability level at the process level.

The model is based on the prior literature on IT business value, as this approach provides insight into how 
complementary resources create value at the process level in terms of capabilities. It also describes a hierarchy of resources and capabilities and how they are related to one another.

In this model, the resources are IT and social media assets (tangible and intangible) that interact with and complement each other to create value at the process level in terms of capabilities, which are social media resources generated at two levels: operational and dynamic capabilities.

For social media resources to create value at the process level, certain conditions must be satisfied regarding organizational factors [38] such as management's commitment to innovation, which is considered as a mediator between social media resources and capabilities.

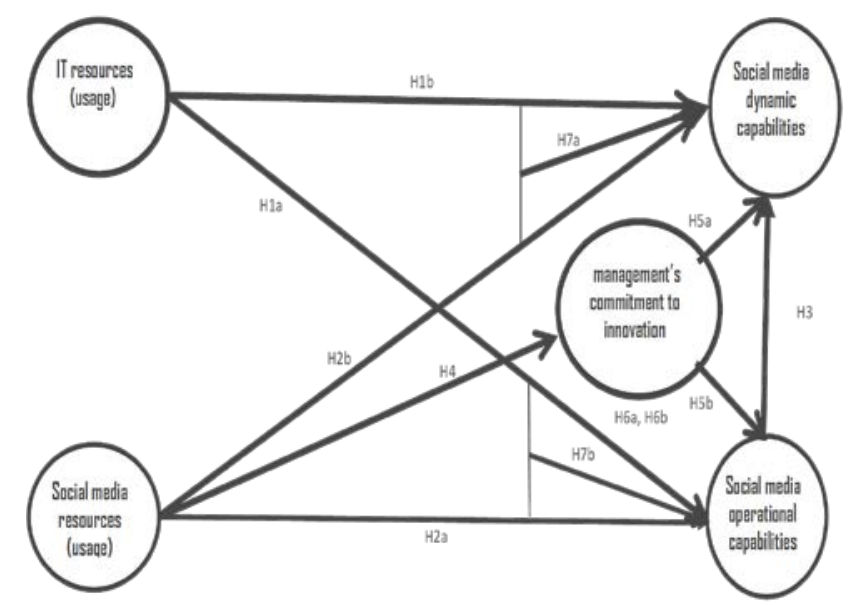

Fig. 1. Research Model.

\section{RESEARCH METHODOLOGY}

\section{A. Sampling and Data Collection}

Data were collected through a questionnaire that was distributed to people with comprehensive insights on the organization of Saudi SMEs, such as managers, owners and senior staff members. The questionnaire was initially distributed by email, but very few responses were received, so other electronic methods were used, such as messages through WhatsApp, Twitter, Instagram and Facebook. To increase the response rate, individuals known to organizations' managers were recruited because they could easily allow the collection of data.

Of approximately 2,000 distributed questionnaires, 301 were returned. The questionnaire was distributed to diverse respondents to attempt to cover SMEs in different sectors. The distribution of respondents is as follows: $87.4 \%$ were male, $86.4 \%$ were aged from $35-45$ years, and $77 \%$ have a bachelor's degree or college diploma certificate. The distribution of the sector in which respondents work is as follows: $7.7 \%$ in the manufacturing industry, $9 \%$ in financial services, $8.3 \%$ in investment services, $6 \%$ in IT services, $15.3 \%$ in retail, $6.7 \%$ in professional and technical services, $14 \%$ in construction services and 33\% in other sectors.

\section{B. Survey Instrument}

All items in the survey questionnaire were taken from previous studies and adapted to reflect the environment in which Saudi SMEs operate. The key items of the questionnaire were measured through five-point Likert scales, and the questionnaire was divided into six parts. The first part focused on general information about the manager or owner of the enterprise and the enterprise itself. The second part covered social media resources and the third part concentrated on IT. The fourth focused on social media capabilities subdivided into customer relation capabilities, marketing capabilities, production and operational capabilities, technological capabilities, strategic capabilities, knowledge management capabilities, and collaboration and innovation capabilities. The fifth part covered the management commitment to innovation.

Applying Agnihotri et al.'s [39] procedure, which is especially relevant to SMEs, we selected the top social media platforms since these have a large audience.

Eight social media platforms were chosen to reflect the usage of social media resources in KSA SMEs: Facebook, Twitter, LinkedIn, YouTube, WhatsApp, blogs, Snapchat and Instagram. The nature of social media usage, which comprises a variety of types and dimensions, and social media resources are distinct uncorrelated factors. Accordingly, social media resources can be treated as the formative construct, as suggested by Hu and Zhang [40].

The classification of IT resources was adapted from Bardhan et al. [41] to reflect commonly used IT resources in SMEs in KSA. Their approach uses a wide range of IT resources to measure the usage of basic communications technology, group collaboration technology and enterprise computing technology. This broad view of IT usage enables a comprehensive evaluation of how IT resources affect social media at the process level. This construct is considered a reflecting construct, as suggested by Wetering et al. [42].

Social media capabilities were classified into two levels by adapting Protogerou et al.’s [19] classification of capabilities, whom classified them into dynamic and operational capabilities.

In this study, the selected social media dynamic capabilities are those considered necessary for the adaption of an organization's essential processes in a business environment changing due to circumstances such as technological change, including social media innovation and collaborative capabilities [43], social media strategic capabilities [19], and social media knowledge management capabilities [44]. The scale used to rate the social media dynamic capabilities was adapted from Yang and Chen [45], Nguyen et al. [24], Wong et al. [43] and Wang et al. [2].

Social media operational capabilities result from the use of social media to produce goods and services [19]. Operational capabilities were measured through four items: social media production and operational capabilities; social media marketing capabilities; social media customer relationship capabilities; and social media technological capabilities. These items were adapted from Schaupp and Bélanger [17], Trainor et al. [10], Kane [46], Wong et al [43], Marzouk [31] and Wang and Kim [18]. Following prior research, social media capabilities were modelled as reflective constructs [17]. 
The scale of management's commitment to innovation was adapted from Nybakk et al. [34] and is considered a reflective construct, as suggested by Schaupp and Bélanger [17].

\section{Analysis}

Partial least squares structural equation modeling analysis was used because of its ability to deal with complex models combining correlations between several constructs and explicit variables, such as interaction and mediation effects, and handle both reflective and formative scales with high predictive accuracy and lower risk than other regression techniques that predict cause-and-effect relationships [47]. Moreover, this modeling technique can handle exploratory models of theories in the early stages of development [47], such as the business value approach considered in this study. Following Chin [48] and Hair et al. [47], the model was analyzed in two stages. The first stage assessed the model's reliability, convergent validity and discriminant validity, and the second stage tested the structural model. Since the research model contains both formative and reflective constructs, each type must be treated differently during evaluation [47].

The reflective constructs were assessed through construct validity, reliability, convergent validity and discriminant validity. Table I presents the results of construct reliability and validity. To confirm convergent validity, the factor loading must be above 0.7, composite reliability (CR) should be higher than 0.7 and average variance extracted (AVE) should be higher than 0.5 [47]. Following Hair et al. [47], a Cronbach's alpha value of 0.7 is considered acceptable. The results in Table I indicate that the model satisfies the requirements for both reliability and convergent validity.

TABLE I. FACTOR LOADING, RELIABILITY AND VALIDITY

\begin{tabular}{|c|c|c|c|c|c|}
\hline $\begin{array}{l}\text { Factors } \\
\text { and } \\
\text { Items }\end{array}$ & \multicolumn{2}{|c|}{ Factor Loadings } & $\begin{array}{l}\text { Cronbach's } \\
\text { Alpha }\end{array}$ & $\mathbf{C R}$ & AVE \\
\hline \multicolumn{3}{|c|}{ Organizational factor (OF) } & 0.876 & 0.915 & 0.730 \\
\hline OF1 & 0.885 & & & & \\
\hline OF2 & 0.890 & & & & \\
\hline OF3 & 0.879 & & & & \\
\hline OF4 & 0.756 & & & & \\
\hline \multicolumn{3}{|c|}{ Social media dynamic capabilities (SMDC) } & 0.964 & 0.968 & 0.655 \\
\hline \multicolumn{5}{|c|}{ Social media innovation and collaborative capability (SMDc) } & \\
\hline SMDc1 & & 0.848 & & & \\
\hline SMDc2 & & 0.852 & & & \\
\hline SMDc3 & & 0.851 & & & \\
\hline SMDc4 & & 0.840 & & & \\
\hline \multicolumn{6}{|c|}{$\begin{array}{l}\text { Social media knowledge } \\
\text { capability (SMDk) }\end{array}$} \\
\hline SMDk1 & & 0.819 & & & \\
\hline SMDk2 & & 0.835 & & & \\
\hline SMDk3 & & 0.823 & & & \\
\hline SMDk4 & & 0.827 & & & \\
\hline \multicolumn{6}{|c|}{$\begin{array}{l}\text { Social media strategic } \\
\text { capability }\end{array}$} \\
\hline SMDs1 & & 0.843 & & & \\
\hline SMDs2 & & 0.833 & & & \\
\hline
\end{tabular}

\begin{tabular}{|c|c|c|c|c|c|c|}
\hline SMDs3 & & 0.791 & & & & \\
\hline SMDs4 & & 0.829 & & & & \\
\hline \multicolumn{4}{|c|}{ Social media operational capabilities (SMP) } & 0.968 & 0.971 & 0.674 \\
\hline \multicolumn{2}{|c|}{$\begin{array}{l}\text { Social media marketing } \\
\text { capability } \backslash(\mathrm{SMPm})\end{array}$} & & & & & \\
\hline SMPm1 & & & 0.825 & & & \\
\hline SMPm2 & & & 0.842 & & & \\
\hline SMPm3 & & & 0.835 & & & \\
\hline SMPm4 & & & 0.847 & & & \\
\hline \multicolumn{7}{|c|}{ Social media customer relationship management capability (SMPo) } \\
\hline SMPo1 & & & 0.849 & & & \\
\hline SMPo2 & & & 0.778 & & & \\
\hline SMPo3 & & & 0.846 & & & \\
\hline SMPo4 & & & 0.807 & & & \\
\hline \multicolumn{7}{|c|}{ Social media production and operational capability (SMPp) } \\
\hline SMPp1 & & & 0.831 & & & \\
\hline SMPp2 & & & 0.808 & & & \\
\hline SMPp3 & & & 0.815 & & & \\
\hline SMPp4 & & & 0.818 & & & \\
\hline \multicolumn{7}{|c|}{ Social media technological capability (SMPt) } \\
\hline SMPt1 & & & 0.852 & & & \\
\hline SMPt2 & & & 0.752 & & & \\
\hline SMPt3 & & & 0.811 & & & \\
\hline MPt4 & & & 0.813 & & & \\
\hline $\begin{array}{l}\text { IT } \\
\text { resource } \\
\text { usage } \\
\text { (SMR) }\end{array}$ & & & & 0.872 & 0.907 & 0.662 \\
\hline SMR1 & 0.821 & & & & & \\
\hline SMR2 & 0.788 & & & & & \\
\hline SMR3 & 0.865 & & & & & \\
\hline SMR4 & 0.799 & & & & & \\
\hline
\end{tabular}

Table II presents the results for discriminant validity, which was assessed by comparing the AVEs for correlations and other latent constructs, as suggested by Hair et al. [47].

Based on the results in Table II, just one value does not satisfy the requirements of discriminate validity. However, taking these findings in combination with the confirmatory factor analysis results in Table I, the model can be considered valid [49].

The formative constructs were examined through weights and variance inflation factors (VIFs) to test for multicollinearity, as suggested by Hair et al. [47]. Table III presents the results.

As Table III shows, all the social media resources satisfy the condition of VIF being less than 5 [47]. Although some indicators do not show significant output for the weight value, they were not removed from the model following Chin's [48] criteria.

The second stage of the analysis involved testing the structural model using a bootstrapping technique. Interaction effects were tested through the latent variable modeling approach recommended by Hair et al. [47]. The mediating 
effects of organizational factors on the relationships between social media resources and IT resources were also tested following the procedure suggested by Hair et al. [47].

Further analysis was conducted to ensure the significance of specific indirect effects through manual calculations of the standard error. This method is recommended by Hair et al. [47]. Table IV presents the results for both direct effects and the specific indirect effects.

Referring to Table IV, the relationship between social media resources and social media operational capabilities was significant $(\beta=-0.143, p<0.020)$ while the relationship between social media resources and dynamic capabilities was not significant $(\beta=0.048, \mathrm{p}<0.146)$. Thereby, $\mathrm{H} 1$ is partially supported. The results in Table IV also give support to $\mathrm{H} 2$ as the relationship between IT resources and social media operational $(\beta=0.414, \mathrm{p}<0.000)$ and dynamic capabilities $(\beta$ $=0.074, \mathrm{p}<0.083)$ was significant. Social media operational capabilities had a significant impact on social media dynamic capabilities $(\beta=0.642, p<0.000)$, supporting H3. Social media resources had a significant impact on management commitment ( $\beta=-0.242, p<0.015$ ), thus supporting H4. H5 is supported due to significant relationship between management's commitment to innovation and both social media dynamic capabilities $(\beta=0.289, \mathrm{p}<0.000)$ and operational capabilities $(\beta=0.445, \mathrm{p}<0.000)$. The results for indirect effects provide support for the mediating effect predicted by hypothesis H6a and reject hypothesis H6b. The impact of the interaction effects between social media and IT resources on social media operational capabilities $(\beta=0.083$, $p$ $<0.568)$ and dynamic capabilities $(\beta=-0.099$, $\mathrm{p}<0.498)$ was not significant and, thus, H7 is not supported.

TABLE II. DISCRIMINANT VALIDITY TEST

\begin{tabular}{|l|l|l|l|l|}
\hline Variables & SMR & OF & SMDC & SMP \\
\hline SMR & 0.814 & & & \\
\hline OF & 0.588 & 0.854 & & \\
\hline SMDC & 0.704 & 0.792 & 0.809 & \\
\hline SMP & 0.713 & 0.711 & 0.896 & 0.821 \\
\hline
\end{tabular}

TABLE III. VALIDITY ANALYSIS OF FORMATIVE CONSTRUCTS

\begin{tabular}{|l|l|l|l|}
\hline $\begin{array}{l}\text { Social Media Resources } \\
\text { (SOMR) }\end{array}$ & $\begin{array}{l}\text { Standardized } \\
\text { Loading }\end{array}$ & P Value & VIF \\
\hline Blog & 0.333 & 0.049 & 1.188 \\
\hline Facebook & -0.424 & 0.031 & 1.096 \\
\hline Instagram & -0.053 & 0.701 & 1.250 \\
\hline LinkedIn & 0.271 & 0.065 & 1.180 \\
\hline Snapchat & -0.006 & 0.963 & 1.204 \\
\hline Twitter & -0.131 & 0.434 & 1.251 \\
\hline YouTube & 0.654 & 0.002 & 1.177 \\
\hline WhatsApp & 0.016 & 0.914 & 1.089 \\
\hline
\end{tabular}

TABLE IV. SUMMARY OF HYPOTHESES TESTING RESULTS

\begin{tabular}{|l|l|l|l|l|l|}
\hline \multicolumn{1}{|l|}{ Direct Effect } & $\begin{array}{l}\text { Original } \\
\text { Sample } \\
(\mathrm{O})\end{array}$ & $\begin{array}{l}\text { Sample } \\
\text { Mean } \\
(\mathrm{M})\end{array}$ & $\begin{array}{l}\text { Standard } \\
\text { Deviation } \\
\text { (STDEV) }\end{array}$ & $\begin{array}{l}\text { T Statistics } \\
(\mid \mathrm{O} / \text { STDEV|) }\end{array}$ & P Values \\
\hline $\begin{array}{l}\text { SMR -> } \\
\text { SMDC }\end{array}$ & 0.074 & 0.070 & 0.043 & 1.734 & $0.083^{*}$ \\
\hline $\begin{array}{l}\text { SMR -> } \\
\text { SMP }\end{array}$ & 0.414 & 0.397 & 0.074 & 5.558 & $0.000^{* * *}$ \\
\hline $\begin{array}{l}\text { Interaction } \\
\text { 2 (SOMR } \\
\text { SMR) -> } \\
\text { SMP }\end{array}$ & 0.083 & -0.014 & 0.145 & 0.571 & 0.568 \\
\hline $\begin{array}{l}\text { Interaction1 } \\
\text { SOMR } * \\
\text { SMR) -> } \\
\text { SMDC }\end{array}$ & -0.099 & -0.013 & 0.146 & 0.677 & 0.498 \\
\hline $\begin{array}{l}\text { OF -> } \\
\text { SMDC }\end{array}$ & 0.289 & 0.293 & 0.053 & 5.471 & $0.000^{* * *}$ \\
\hline OF -> SMP & 0.445 & 0.436 & 0.069 & 6.409 & $0.000^{* * *}$ \\
\hline $\begin{array}{l}\text { SMP -> } \\
\text { SMDC }\end{array}$ & 0.642 & 0.634 & 0.060 & 10.771 & $0.000^{* * *}$ \\
\hline $\begin{array}{l}\text { SOMR -> } \\
\text { SMR }\end{array}$ & -0.373 & -0.374 & 0.124 & 3.012 & $0.003^{* * *}$ \\
\hline $\begin{array}{l}\text { SOMR -> } \\
\text { OF }\end{array}$ & -0.242 & -0.254 & 0.099 & 2.431 & $0.015^{* * *}$ \\
\hline $\begin{array}{l}\text { SOMR -> } \\
\text { SMDC }\end{array}$ & 0.048 & 0.042 & 0.033 & 1.453 & 0.146 \\
\hline $\begin{array}{l}\text { SOMR -> } \\
\text { SMP }\end{array}$ & -0.143 & -0.122 & 0.062 & 2.321 & $0.020^{* * *}$ \\
\hline Indirect Effect & -0.070 & -0.075 & 0.033 & 2.114 & 0.035 \\
\hline $\begin{array}{l}\text { SOMR -> } \\
\text { OF -> } \\
\text { SMDC }\end{array}$ & -0.107 & -0.111 & 0.049 & 2.174 & 0.030 \\
\hline $\begin{array}{l}\text { SOMR -> } \\
\text { OF -> SMP }\end{array}$ & \\
\hline
\end{tabular}

\section{Discussions AND CONCLUSIONS}

This study investigates how social media resources complement and interact with other IT resources to create value at the process level in Saudi SMEs.

This paper is unlike previous social media process-level studies, which focused on processes management and process culture and did not devote sufficient attention to how value is created [50].

The results of this study indicate that management's commitment to innovation mediates the relationships between social media resources and social media dynamic capabilities. Thus, management's commitment to innovation is a necessary condition for creating dynamic capabilities. This implies that strong commitment from management to innovation can facilitate the usage of social media resources to create dynamic capabilities at the process level. The literature suggests that managers who are committed to innovation are willing to accept risk [51]. Thus, SME managers willing to accept risk and who support innovation can build dynamic capabilities that can create change in an organization. This contrasts with some IT business value scholars, such as Tallon et al. [38], who claim that management committed to innovation must interact with social media resources to create value at the process level. 
The interaction between social media resources and IT resources was not found to contribute to value generation at the process level. This contradicts the findings of Trainor et al. [10] and can be attributed to the consideration of the characteristics of SMEs that engage in limited use of information systems [52]. Thus, SMEs in KSA do not benefit from investment in IT and social media to generate synergies at the process level. Accordingly, IT designers should focus on developing IT applications that can be integrated with social media applications and be easily used by SMEs at a low cost.

Although the results of this study demonstrate that the interaction of IT resources and social media resources is not a predictor of social media process-level capabilities, IT resources do contribute to building social media operational and dynamic capabilities, which is aligned with the results of previous studies such as Trainor et al. [10]. This indicates different attributes make different contributions to building new social media capabilities without interacting with one another. Thus, organizations can create unique value if they focus on integrating social media platforms with IT resources.

The results suggest that social media resources directly affect dynamic capabilities because social media can facilitate communication and collaboration and diffuse knowledgerelated competencies. This power of connectivity enables organizations to connect to their trading partners, customers and employees, transforming the information that is communicated among these groups. Thus, this enables innovation regarding management's knowledge and creates new opportunities for the company to create business value. This indicates that the way dynamic capabilities are built depends on how individuals choose to use technology [46].

The findings reveal the direct impact of social media resources on social media operational capabilities, such as marketing, customer relationship capabilities, operational capabilities and technological capabilities. This indicates social media can support a firm's operational capabilities and connect it with customers, suppliers and employees. This finding is not surprising as KSA has good internet infrastructure available to customers at suitable prices, which enables the use of mobile and other electronic devices in the work environment.

In summary, the findings indicate that social media resources directly contribute to generating business value at the process level in terms of both operational and dynamic capabilities, which is consistent with Trainor et al. [10]. This can enable SME managers to take steps to introduce social media in the organization to achieve competitive advantage.

Social media operational capabilities contribute to building dynamic capabilities, which supports the hierarchy of resources discussed by Wang and Ahmed [44] and Protogerou et al. [19]. Overall, the results indicate that social media can transform the way firms work at the process level. Thus, the findings support the dynamic capabilities framework proposed by Wilden et al. [53], who indicated building dynamic capabilities requires a routine in terms of operational capabilities.

The study has several managerial implications. First, this research represents a first step toward identifying social media capabilities and determining how they are generated from the perspective of the organization. This enables managers to think about integrating social media operational capabilities into business processes to achieve business goals. This will enable business decision-makers and IT designers to recognize the process capabilities and conditions under which the organization can generate business value from social media. Accordingly, criteria for the effective use of social media can be identified. Second, the results explain how social media usage contributes to generating dynamic capabilities, showing the importance of the role of the innovative manager in building this capability, which is one of the strategic capabilities that can generate competitive advantage. This suggests the SME managers can use innovative techniques to build dynamic capabilities from social media to face the competitors and the changing environments. Third, managers and IT designers can use the results of the study to align social media capabilities with other organizational capabilities to build strategies to maximize the value generated for the organization. This advances the suggestion that SMEs need a new business model that integrates social media with organizational goals. Overall, investigating, the value creation process can lead to recommendations on best practices. Fourth, the model describes complex relations between resources and capabilities to generate some operational and adaptive dynamic capabilities; this proposes that, whenever complex relationships between resources exist, this will lead to generating new capabilities that are not easily replicated, as suggested by RBV, thus, managers can use their innovation to build this complex interaction. Future researches should focus on this complex interaction to provide more insight into the value creation process.

Fifth, the findings can also support national-level strategic plans to increase the contribution of SMEs to KSA's economic growth through social media-based e-commerce [1], through giving the necessary support for use the social media in ecommerce.

The study has many empirical impactions. This result supports social network theory, which suggests that management's commitment to innovation mediates the relationships between social media usage and business value. The findings also support the dynamic capability approach by enabling exploration of managers' role in creating dynamic capabilities, as proposed by Schilke et al. [54].

This study contributes to the literature on social media business value in several ways. To the best of the researchers' knowledge, this is the first study to highlight the attributes of both social media and IT interaction and the mediating role of management's commitment to innovation to create new business value at the process level. Considering different theories can enhance the explanation of how organizational factors can affect value generation at the process level. This gives boundaries to the theory of social media business value, as recommended by Andersson, Cuervo-Cazurra, and Nielsen [55]. The study empirically tests knowledge gaps in the IT business value literature, such as the mechanism by which business value is created through social media at the process level by the disaggregation of social media resources at different levels, as discussed by Schryen [9]. Accordingly, it can be used as a starting point for future research. 
In general, this study sheds light on operational capabilities that have not been given sufficient attention in previous social media studies by focusing on capabilities such as customer relationship capabilities and marketing capabilities [18].

\section{FUTURE RESEARCH}

The results present many challenges for scholars, including the impacts of organizational and environmental factors, and the interactions between these factors, on the relationships between social media resources and capabilities. Future research should investigate interaction effects of social media and IT resources in organizations of different sizes and with different characteristics.

The research model presents a comprehensive, hierarchical list of social media capabilities that can be used in future researches. It should also be noted that the research model neglects the impacts of other organizations' resources and capabilities on value creation through social media at the process level. Thus, future research should focus on how different organizational capabilities contribute to value generation in organizations of different sizes and with different characteristics.

Longitudinal studies could provide insight into how value is generated at the process level and, specifically, how social media dynamic capabilities evolve. Thus, by implementing the research model in different industries and countries, future studies could yield findings that enable the design of effective social media strategies, reducing the knowledge gap between the potential and actual use of social media in business and increasing understanding of how it can create value for organizations [56].

\section{ACKNOWLEDGMENT}

The authors are thankful to the Deanship of Scientific Research at University of Bisha Saudi Arabia for funding this work through the Research Project under Grant Number (UB115-1438).

\section{REFERENCES}

[1] S. Abed, Y. Dwivedi and M. Williams, "Social commerce as a business tool in Saudi Arabia's SMEs," International Journal of Indian Culture and Business Management, vol. 13, no. 1, pp. 1-19, 2016.

[2] Y. Wang, M. Rod, S. Ji and Q. Deng, "Social media capability in B2B marketing: toward a definition and a research model," Journal of Business \& Industrial Marketing, vol. 32, no. 8, pp. 1125-1135, 2017.

[3] Trkman and P. Trkman, "A framework for increasing business value from social media", Economic Research-Ekonomska Istraživanja, vol. 31, no. 1, pp. 1091-1110, 2018.

[4] Braojos-Gomez, J. Benitez-Amado and F. Javier Llorens-Montes, "How do small firms learn to develop a social media competence?," International Journal of Information Management, vol. 35, no. 4, pp. 443-458, 2015.

[5] P. Appiahene, N. Ussiph and Y. Missah, "Information Technology Impact on Productivity:A Systematic Review and Meta-Analysis of the Literature", International Journal of Information Communication Technologies and Human Development, vol. 10, no. 3, pp. 39-61, 2018. Available: 10.4018/ijicthd.2018070104.

[6] D. de Lima Oliveira and A. Maçada, "IT capabilities' business value: analysis of multi-level performance in Brazilian organization,s" Gestão \& Produção, vol. 24, no. 2, pp. 295-309, 2017.
[7] N. Melville, K. Kraemer and V. Gurbaxani, "Review: Information Technology and Organizational Performance: An Integrative Model of IT Business Value," MIS Quarterly, vol. 28, no. 2, p. 283, 2004.

[8] M. Queiroz, "Business process and IT cospecialization: Conceptualization and suggestions for future research," in 23rd Americas Conference on Information Systems, Boston, Massachusetts, USA, 2017.

[9] G. Schryen, "Revisiting IS business value research: what we already know, what we still need to know, and how we can get there," European Journal of Information Systems, vol. 22, no. 2, pp. 139-169, 2013.

[10] K. Trainor, J. Andzulis, A. Rapp and R. Agnihotri, "Social media technology usage and customer relationship performance: A capabilities-based examination of social CRM," Journal of Business Research, vol. 67, no. 6, pp. 1201-1208, 2014.

[11] L. Hsieh et al., "A multidimensional perspective of SME internationalization speed: The influence of entrepreneurial characteristics," International Business Review, vol. 28, no. 2, pp. 268283, 2019. Available.

[12] Y. Wang, S. Shi, S. Nevo, S. Li and Y. Chen, "The interaction effect of IT assets and IT management on firm performance: A systems perspective," International Journal of Information Management, vol. 35, no. 5, pp. 580-593, 2015.

[13] H. Mao, S. Liu, J. Zhang and Z. Deng, "Information technology resource, knowledge management capability, and competitive advantage: The moderating role of resource commitment," International Journal of Information Management, vol. 36, no. 6, pp. 1062-1074, 2016.

[14] A. Kaplan and M. Haenlein, "Users of the world, unite! The challenges and opportunities of Social Media," Business Horizons, vol. 53, no. 1, pp. 59-68, 2010.

[15] S. Kargaran, M. Jami Pour and H. Moeini, "Successful customer knowledge management implementation through social media capabilities," VINE Journal of Information and Knowledge Management Systems, vol. 47, no. 3, pp. 353-371, 2017.

[16] N. Wittkuhn, T. Lehmkuhl, T. Küpper and R. Jung, "Social CRM performance dimensions: A resource-based view and dynamic capabilities perspective," in 28th BLED e-conference, Bled, Slovenia, 2015.

[17] C. Schaupp, J. Dorminey and R. Dull, "A resource-based view of using social media for material disclosures," in 48th Hawaii International Conference on System Sciences, Hawaii, USA, 2015.

[18] Z. Wang and H. Kim, "Can Social Media Marketing Improve Customer Relationship Capabilities and Firm Performance? Dynamic Capability Perspective," Journal of Interactive Marketing, vol. 39, pp. 15-26, 2017.

[19] A. Protogerou, Y. Caloghirou and S. Lioukas, "Dynamic capabilities and their indirect impact on firm performance," Industrial and Corporate Change, vol. 21, no. 3, pp. 615-647, 2011.

[20] E. Bendoly, A. Bharadwaj and S. Bharadwaj, "Complementary Drivers of New Product Development Performance: Cross-Functional Coordination, Information System Capability, and Intelligence Quality," Production and Operations Management, vol. 21, no. 4, pp. 653-667, 2011.

[21] P. Wójcik, "Exploring Links Between Dynamic Capabilities Perspective and Resource-Based View: A Literature Overview," International Journal of Management and Economics, vol. 45, no. 1, pp. 83-107, 2015.

[22] J. Benitez, A. Castillo, J. Llorens and J. Braojos, "IT-enabled knowledge ambidexterity and innovation performance in small U.S. firms: The moderator role of social media capability," Information \& Management, vol. 55, no. 1, pp. 131-143, 2018.

[23] A. Rathore and P. Ilavarasa, "Social media and business practices", Encyclopaedia of Information Science and Technology. IGI Global., USA, pp. 7126 -7139, 2018.

[24] B. Nguyen, X. Yu, T. Melewar and J. Chen, "Brand innovation and social media: Knowledge acquisition from social media, market orientation, and the moderating role of social media strategic capability," Industrial Marketing Management, vol. 51, pp. 11-25, 2015.

[25] A. Shams Eldin, "The relationships between IT resources and dynamic capabilities: Evidence from Sudanese insurance and banking sectors," 
International Journal of Advanced and Applied Sciences, vol. 7, no. 4, pp. 91-102, 2020.

[26] A. Shams Eldin, A. Hafiez and A. Al-Tit, "Impact of IT Resources on IT Capabilities in Sudanese Insurance and Banking Sectors," International Journal of Advanced Computer Science and Applications, vol. 7, no. 6, 2016.

[27] S. Chatterjee and A. Kumar Kar, "Why do small and medium enterprises use social media marketing and what is the impact: Empirical insights from India," International Journal of Information Management, vol. 53, p. 102103, 2020.

[28] M. Pour, E. Mamani and M. Rahimzadeh, "How Customer Relationship Management (CRM) and Innovation Influence Business Performance Mediating Role of Innovation," International Journal of Customer Relationship Marketing and Management, vol. 9, no. 2, pp. 1-15, 2018.

[29] S. Toriani and M. Angeloni, "CRM as a Support for Knowledge Management and Customer Relationship," JISTEM Journal of Information Systems and Technology Management, vol. 8, no. 1, pp. 87108, 2011.

[30] C. Cheng and E. Shiu, "How to enhance SMEs customer involvement using social media: The role of Social CRM," International Small Business Journal: Researching Entrepreneurship, vol. 37, no. 1, pp. 2242, 2018.

[31] W. Marzouk, "Usage and Effectiveness of Social Media Marketing in Egypt : An Organization Perspective," Jordan Journal of Business Administration, vol. 12, no. 1, pp. 209-238, 2016.

[32] Wade and J. Hulland, "Review: The Resource-Based View and Information Systems Research: Review, Extension, and Suggestions for Future Research," MIS Quarterly, vol. 28, no. 1, p. 107, 2004.

[33] A. Quaadgras, P. Weill and J. Ross, "Management Commitments that Maximize Business Impact from IT," Journal of Information Technology, vol. 29, no. 2, pp. 114-127, 2014.

[34] E. Nybakk, P. Crespell, E. Hansen and A. Lunnan, "Antecedents to forest owner innovativeness: An investigation of the non-timber forest products and services sector,"Forest Ecology and Management, vol. 257, no. 2, pp. 608-618, 2009.

[35] M. Clark and J. Melancon, "The Influence of Social Media Investment on Relational Outcomes: A Relationship Marketing Perspective," International Journal of Marketing Studies, vol. 5, no. 4, 2013.

[36] A. MorettI, and A. Tuan, "Social media marketing and relationship marketing: revolution or evolution? A first step analysis", Sinergie Italian Journal of Management, no. 93, pp. 115-137, 2018.

[37] R. Ryssel, T. Ritter and H. Georg Gemünden, "The impact of information technology deployment on trust, commitment and value creation in business relationships," Journal of Business \& Industrial Marketing, vol. 19, no. 3, pp. 197-207, 2004.

[38] P. Tallon, M. Queiroz, T. Coltman and R. Sharma, "Business Process and Information Technology Alignment: Construct Conceptualization, Empirical Illustration, and Directions for Future Research," Journal of the Association for Information Systems, vol. 17, no. 9, pp. 563-589, 2016.

[39] R. Agnihotri, R. Dingus, M. Hu and M. Krush, "Social media: Influencing customer satisfaction in B2B sales," Industrial Marketing Management, vol. 53, pp. 172-180, 2016.

[40] T. Hu and P. Ping, "Social media usage as a formative construct: Conceptualization, validation and implication," Journal of Information Technology Management, vol. 4, no., pp. 151-164, 2016.
[41] I. Bardhan, V. Krishnan and S. Lin, "Project Performance and the Enabling Role of Information Technology: An Exploratory Study on the Role of Alignment," Manufacturing \& Service Operations Management, vol. 9, no. 4, pp. 579-595, 2007.

[42] V. Weterin, R. Versendaal and P. Walraven, "Examining hospital's IT infrastructure capability and digital capabilities: A resource-based perspective," in 24th Americas Conference on Information Systems., New Orleans, Louisiana, USA, 2018.

[43] C. Wong, K. Lai, T. Cheng and Y. Lun, "The role of IT-enabled collaborative decision making in inter-organizational information integration to improve customer service performance," International Journal of Production Economics, vol. 159, pp. 56-65, 2015.

[44] C. Wang and P. Ahmed, "Dynamic capabilities: A review and research agenda,"International Journal of Management Reviews, vol. 9, no. 1, pp. 31-51, 2007.

[45] C. Yang and L. Chen, "Can organizational knowledge capabilities affect knowledge sharing behavior?," Journal of Information Science, vol. 33, no. 1, pp. 95-109, 2007.

[46] C. Kane, "Enterprise social media: Current capabilities and future possibilities," MIS Quarterly Executive, vol. 14, no. 1, pp. 1-16, 2015.

[47] Hair, G. Hult, C. Ringle and M. Sarstedt, A primer on partial least squares structural equation modeling (PLS-SEM). Los Angeles: SAGE, 2017.

[48] W. Chin, "How to write up and report PLS analyses", in Handbook of partial least squares concepts, methods and applications, Berlin: Springer, 2010, pp. 655-690.

[49] A. Farrell and J. Rudd, "Factor analysis and discriminant validity: A brief review of some practical issues," in Australia-New Zealand Marketing Academy Conference., 2009.

[50] J. Prodanova and A. Van Looy, "How Beneficial is Social Media for Business Process Management? A Systematic Literature Review," IEEE Access, vol. 7, pp. 39583-39599, 2019.

[51] A. Sikora and E. Nybakk, "Rural development and forest owner innovativeness in a country in transition: Qualitative and quantitative insights from tourism in Poland," Forest Policy and Economics, vol. 15, pp. 3-11, 2012.

[52] A. Bahaddad, L. Houghton and S. Drew, "Attracting Customer in Saudi Arabia to Buy from Your Business Online," International Journal of Business and Management, vol. 8, no. 7, 2013.

[53] R. Wilden, T. Devinney and G. Dowling, "The Architecture of Dynamic Capability Research: Identifying the Building Blocks of a Configurational Approach," SSRN Electronic Journal, 2016.

[54] O. Schilke, S. Hu and C. Helfat, "Quo Vadis, Dynamic Capabilities? A Content-Analytic Review of the Current State of Knowledge and Recommendations for Future Research," Academy of Management Annals, vol. 12, no. 1, pp. 390-439, 2018.

[55] U. Andersson, A. Cuervo-Cazurra and B. Nielsen, "From the Editors: Explaining interaction effects within and across levels of analysis," Journal of International Business Studies, vol. 45, no. 9, pp. 1063-1071, 2014.

[56] S. Ketonen-Oksi, J. Jussila and H. Kärkkäinen, "Social media based value creation and business models," Industrial Management \& Data Systems, vol. 116, no. 8, pp. 1820-1838, 2016. 